\title{
Mental health \& Social issues of infected male member of HIV+ve discordant couple - A qualitative study
}

\author{
Kadiresan.M.S ${ }^{1}$, Dr.Relton. ${ }^{2}$ \\ ${ }^{\text {I}}$ (Department of Socialwork, Doctoral Scholar, Bishop Heber College (Autonomous), Bharathidasan University, \\ Trichirappalli, Tamilnadu.) \\ ${ }^{2}$ (Department of Socialwork, Associate Professor \& Head, Bishop Heber College (Autonomous), Bharathidasan
} University, Trichirappalli, Tamilnadu.)

\begin{abstract}
In India 2.4 million people are infected with HIV. Increasing trend is observed in HIV scenario because of more number of new infections are identified. This is due to an infected person spreads the virus to uninfected persons through unprotected sex and unsterilized needle use etc,. Out of 2.4 million, it is estimated that $61 \%$ are male and $39 \%$ are female. This may predict that the serodiscordant couple are living more in number with psychological and social problems due to various reasons but less number of interventions are designed and implemented exclusive for male infected persons of the same category. The purpose of the qualitative study is to identify those predominant problems and suggestions for remedial measures.
\end{abstract}

Keywords: HIV serodiscordant, psychological \& social issues, male infected persons.

\section{Introduction:}

The HIV/AIDS pandemic is not only threatening the physical health of the millions of People Living with HIV (PLHIV) globally or in India. They were also threatening by Psychological and social issues. 2.4 million People are HIV positive in India. It's estimated that out of these $61 \%$ are male, $39 \%$ are female and $3.5 \%$ are children. As of 2009, the adult prevalence is believed to be $0.31 \%$. (Source: AIDS Alliance). 'Serodiscordant couple' is described as one member is infected by HIV the other member is uninfected'. There are many interventions in the field of medical, social and psychological as trials to prevent further spreading of HIV from infected person to uninfected persons through unprotected sexual intercourse. Recent studies are shown that new infections are increasing from the past. Those interventions are focusing the uninfected person. Less number of common interventions is developed and practicing to address the psychological and sociological issues for infected person among discordant couple. Status disclosure plays a vital role to develop various psycho-social issues between the discordant couple. The purpose of this qualitative study is to focus the psychological and sociological issues predominantly affect and suggest some interventions to overcome those issues of male infected person of serodiscordant couple.

Objectives:

1. To study the predominant psychological and social issues of male HIV infected person of serodiscordant couple

2. To suggests the effective socialwork interventions to overcome those issues.

II. Methodology \& tool used:

Qualitative method was adopted to study the objectives. Focus group discussion is used as a major tool for this study.

Sampling: Male HIV infected person of Serodiscordant couple was recruited from the registered list in a positive network (Community Based Organisation - CBO) located in Chennai. There are 64 members registered in the network. 40 members are accepted and given their consent to participate in the study. There are 5 FGD sessions are planned with 8 to 10 members in each. As per the social science research ethics; informed consent, confidentiality etc., are strictly maintained. The moderator facilitated the groups with the following semi-structured questions to study the issues as specified above. The co-moderator taken notes, recording the discussion and maintain the time ( $\mathrm{min}-1 \mathrm{hr}$ ). Demographic details were received by format circulated to the participants. The researcher provided refreshment and offered an incentive for their active cooperation and participation for this study. 


\section{Questions for qualitative analysis:}

1. How did you feel, when you are informed about your status as HIV positive by Integrated Counseling and Testing Centre (ICTC)?

2. As you had an HIV infection, What did you think frequently during post infection period ?

3. How your HIV positive status affects your normal and regular family life?

4. Explain your feelings about the approaches and responses of your family members with you after disclosed your HIV status with them? Or feelings of those who were not yet to disclose.

Data analysis: The researcher analyzed the collected data in a phased manner. Data were explored using thematic analysis and constant comparative method. (Strauss \& Cobia., 1988, Charmaz., 2006).

\section{Analysis:}

Contextual factors: Most of the participants were unequivocally met the doctors to treat various physical problems but as per the doctor's reference for HIV screening, astonishingly heard the information as HIV positive. Unanticipated information makes them to felt shock also thought that they 'lost their life'. The immediate thought came into their mind was 'threat of death'. Some health complications and traumatic conditions along with those feelings make them stressful. They may also suffering from post traumatic stress problems.

"In 2004, I approached a private doctor for the treatment of fever. I was with fever for around 2 months. I had flu every evening through the night for two months. Those two months I had all blood tests and treatment done, and had a sleepless nights. Finally the doctor treated me for viral fever. He referred me to a private lab for HIV screening. I had gone along with my wife to the private lab; the Lab Technician gave the report directly to me and said, 'you are HIV positive.'

I felt completely down and upset. I didn't utter a word to my wife. I thought about myself and felt that my complete life was shattered. I didn't have proper food for 2 to 3 days and did not like to stay at home. I started to smoke regularly and cry in the walls of toilet.

My wife never uttered a word to me regarding the infection or the sickness. She never bothered to confront or ask me about the infection and its cause. She never ever questioned me about my habits and my life outside the house. She is moody most of the time and just does what I say.

The features of the Major Depressive Disorder, the most common of which are feelings of inadequacy, social withdrawal, guilt or ruminating about past events, irritability or excessive anger, and decreased productivity. In addition to having a depressed mood, at least two of the following symptoms must be present; poor appetite or overeating, insomnia (lack of sleeping) or hypersomnia (sleep excessively), low energy or fatigue, low self esteem, poor concentration or difficulty in making decisions, or feeling hopelessness.(American Psychological Association - APA, 2000).

A person may be depressed if, for more than two weeks, he or she has felt sad, down or miserable most of the time or has lost interest or pleasure in usual activities. (http://www.beyondblue.org.au)

Anxiety and Depressive reactions are commonly documented in men with HIV disease (Miller, 1990) along with associated panic attack, heightened arousal, misinterpretation of physical symptoms, social disengagement, mood swings and isolation. Depression can entrench strained relationships and result in loneliness. This is particularly severe when secrecy shrouds diagnosis. Furthermore, HIV infection may create dramatic changes in sexual behaviour which is not only a loss in itself but may be a lost avenue to new relationship formation.

The whole course of disease may be punctuated with bereavement, from loss of life expectancy, to actual death, to health, future aspirations and childrearing. Given such a scenario, suicidal behavior may well be an issue (Pugh,1992; Sherr, 1995; Smith et al.,1990; Starace, 1995).

"I was branded as HIV positive in 2008. My wife, my son (22), and daughter (18) scolded me by saying, 'I'm not fit for anything'. I was completely shattered and separated from family. I was made to sleep in the 'varandha' with separate bed.

Initially, I was a transport owner and I had won black belt in karate. Now I have left my business and I'm weak. What is life, it is nothing. No one in my family is using my plate and tumbler. I $\mathrm{m}$ unemployed now, I get little money from my wife based on my need. Honestly speaking, I m not taking ART in a regular manner. I frequently quarrel with my wife and sometimes feel suicidal."

"I'm staying in a compound where there are five houses. Our house is just beside the main gate. All my neighbours going through the compound have to cross my home. Being a discordant couple, I had once given an interview in a TV channel and disclosed my status. From the next day onwards everybody in my compound stopped mingling with us. The neighbours' children stopped playing with my son and daughter. When my window was open, neighbours peep through while crossing and they were not allowing my children to their home to play with their children, this irritated and disturbed me. 
People were not aware of HIV infection and had limited knowledge. Discrimination and Stigma of the infection still exists.

"Though my wife and children were negative, they were mentally disturbed. My wife frequently reminded me everything happening was because of me. This mentally disturbed me. Finally I shifted my home from that locality to another area, because of the psychological and social stress."

Indeed, the role of environmental stressors has also been strongly implicated in the onset of this disorder. Social isolation is one of the risk factor. In HIV/AIDS, the major environmental stressors to the PLHIV are, Stigma / Discrimination, societal belief on PLHIV is about this is because of their promiscuous behaviour, and so on. For those reason they may acquire stress. (Social work in mental health an evidence based approach - Bruce A.Thyer and Jhon S.Wodarski, published by John Wiley \& sons, Inc., Hoboken, New Jercy. ISBN 9780471693048)

\section{Key findings}

Psychological: Shock, mental disturbance, feeling sleepy, sleeping disturbance, confusion, thought about the future, suicidal thoughts, anger, and verbal abuse by spouse and family members.

Social: Keeping distance with family members and friends, friendship with infected persons, increase in family responsibility, issues in maintaining relationship with neighbours, spouse and children.

\section{Major suggestion and conclusion:}

The above conditions strongly imply depression, anxiety and stress are the major psychological problem which may due to the social issues like gender influence, poor relationship, lack of family support (especially spouse and children), self and societal isolation existing primarily along with physical problems like opportunistic infections (OIs) due to HIV infection in male HIV positive member of the discordant couple. This may overcome by implementing effective socialwork interventions like Cognitive Behaviour Therapy, Yoga therapy \& gender sensitisation training etc, are exclusively designed for the male HIV positive member of the discordant couple.

\section{References:}

[1] American Psychological Association - APA, 2000

[2] Social work in mental health an evidence based approach - Bruce A.Thyer and Jhon S.Wodarski, published by John Wiley \& sons, Inc., Hoboken, New Jercy. ISBN - 9780471693048.

[3] Indian J Med Res. 2011 December; 134(6): 904-911. Doi: 10.4103/0971-5916.92635

[4] http://www.beyondblue.org.au 